\title{
Evaluation of Capillary Network Abnormalities in Branch Retinal Vein Occlusion by Optical Coherence Tomography Angiography
}

Khaled Mohamed Selim, Ahmed El-Sayed Hudieb, Mahmoud Salah Aldin Aldemardach

Ophthalmology Department, Faculty of Medicine, Al-Azhar University, Cairo, Egypt

Corresponding author: Mahmoud Salah, Tel:00201014896146, Email: msalahbaza@gmail.com

\section{ABSTRACT}

Objectives: Is to detect the vascular morphological changes in the two intra retinal; layers superficial network layer and deep network layer by optical coherence tomography angiography (OCT-A) in cases with acute onset branch retinal vein occlusion (BRVO).

Study Design: An observational cross-sectional study in new Kafer El-Sheikh Ophthalmology Hospital. Population: This study included ten patients with (BRVO) of recent onset within the last three months.

Methods: Demographic data such as age, gender, sex and hypertensive history were obtained. A detailed evaluation of cases including complete anterior segment evaluation and posterior segment evaluation was done. OCT-A and fluorescein angiography (FA) were used to study the vascular morphological changes in the (BRVO) area.

Results: As regarding 5 disc area of retinal ischemia FA detected ischemia in 2 cases (20\%), detected no ischemia in one case (10\%) and was not able to evaluate ischemia in 7 cases $(70 \%)$ compared to OCT-A, that detected the ischemia in the superficial capillary plexus (SCP)in 4 cases (40\%), and detected no ischemia in 6 cases $(60 \%)$, but it detected the ischemia in the deep capillary plexus (DCP) in 6 cases (60\%) and detected no ischemia in 4 cases $(40 \%)$.

Conclusion: Our study demonstrated that OCT-A was superior to FA in detection of macular ischemia in cases with acute onset branch retinal vein occlusion (BRVO), macular ischemia detected in the DCP by OCTA had stronger negative relation with V.A. than that of SCP. By OCT-A macular edema (ME) was present mainly in the DCP compared to SCP.

Keywords: Branch retinal vein occlusion (BRVO), fluorescein angiography (FA) capillary non-perfusion, foveal avascular zone(FAZ), macular ischemia, macular edema(ME), optical coherence tomography angiography(OCT-A), superficial capillary plexus (SCP), deep capillary plexus (DCP).

\section{INTRODUCTION}

Retinal vein occlusion (RVO) is the second most common retinal vascular disorder after diabetic retinopathy ${ }^{1}$. RVO is anatomically classified into three main groups based on the location of venous occlusion (branch, central, and hemi-central ${ }^{(2)}$.

FA is a very important tool for evaluating non-perfusion areas and detecting neovascularization in ischemic (RVO)3. However, the ability to detect microvasculature alterations has been limited by the superposition of the capillary networks and leakage4.

OCT-A allows separating the superficial and deep vascular network, whereas the deep capillary network is barely visible on fluorescein angiography5.

\section{Patients and Methods}

This study was designed to be cross observational study including ten eyes to detect the vascular morphological changes in the branch retinal vein occlusion area in both the superficial and the deep retinal network layers by OCT-A in cases of acute onset BRVO. The study was approved by the Ethics Board of Al-Azhar University.
Each case was subjected to a detailed ocular examination. this assessment included uncorrected visual acuity (UCVA), refraction (automated) and then best corrected visual acuity (BCVA), intraocular pressure (IOP) measurement using applanation tonometer, anterior segment slitlamp examination, posterior segment slit-lamp examination by +78 lens an, color photography fundus examination, fundus Fluorescein angiography (FFA) and OCT-A was performed using (Topcon OCT Triton), 6x6 mm scan was taken centered on the fovea in all cases.

\section{Statistical methods}

Statistical presentation and analysis of the present study was conducted, using the mean, standard deviation and chi-square test by SPSS V.20.

\section{RESULTS}

This study was conducted on 10 eyes of 10 patients (3 males $30 \%$ and 7 females 70\%) (Table1).

Table (1): Sociodemographic data of included patients.

\begin{tabular}{|l|c|c|}
\hline \multicolumn{1}{|c|}{ Sex } & N & \% \\
\hline Male & 3 & 30 \\
\hline Female & 7 & 70 \\
\hline Total & 10 & 100 \\
\hline
\end{tabular}


The mean age of the patients was $50.40 \pm$ 13.53 years (Range 24 to 71 years). The mean time from onset to imaging was $12.40 \pm 4.90$ days (Range $5-20$ days). The mean IOP of the patients was $12.50 \pm 3.72$ (Range $8-20$ ). The mean V.A. of the patients was $0.074 \pm 0.075$ (Range 0.003 0.250) (Table2).

Table (2): General clinical data.

\begin{tabular}{|l|c|c|}
\hline & Range & Mean \pm S.D \\
\hline Age (years) & $24-71$ & $50.40 \pm 13.53$ \\
\hline $\begin{array}{l}\text { Onset of complain } \\
\text { days) }\end{array}$ & $5-20$ & $12.40 \pm 4.90$ \\
\hline IOP (mmHg) & $8-20$ & $12.50 \pm 3.72$ \\
\hline VA (decimal) & $\begin{array}{c}0.003- \\
0.250\end{array}$ & $0.074 \pm 0.075$ \\
\hline
\end{tabular}

5 cases $(50 \%)$ were hypertensive and 5 cases $(50 \%)$ were not hypertensive (Table 3 )

Table (3): Classification of cases according to hypertension as a risk factor.

\begin{tabular}{|l|c|c|}
\hline \multicolumn{1}{|c|}{ Hypertension } & N & \% \\
\hline Yes & 5 & 50 \\
\hline No & 5 & 50 \\
\hline Total & 10 & 100 \\
\hline
\end{tabular}

Mathematically, 5-disc diameter area by FA equal to $(8.85-11.35) \mathrm{mm} 2$, this area corresponds to $3 \times 3 \mathrm{~mm} 2$ of OCT-A scan (a quadrant of 6x6 OCT-A scan)

In our study we stated that the significant macular ischemia by OCT-A in BRVO means that there is an area of macular ischemia extends from the FAZ equal to $9 \mathrm{~mm} 2$ or $3 \times 3 \mathrm{~mm} 2$ (a quadrant of $6 \times 6$ scan), even if there is macular edema within this area.

The macular ischemia was revealed in 2 cases by FA, but the significant macular ischemia was revealed in 4 cases in SCP by OCT-A which included the ischemic 2 cases detected by FA.

The relation between FA and SCP by OCT-A in detection of significant macular ischemia was highly statistically significant (Table 4), this demonstrated that OCT-A is superior to FA especially when retina is obscured by extensive hemorrhage in cases of BRVO.

Table (4): The relation between FA and OCT-A in detection of significant macular ischemia in SCP after classification of cases according to ischemic condition

\begin{tabular}{|l|c|c|c|c|}
\hline \multirow{2}{*}{} & \multicolumn{2}{|c|}{ FA } & \multicolumn{2}{c|}{$\begin{array}{c}\text { significant macular } \\
\text { ischemia in SCP by } \\
\text { OCT-A }\end{array}$} \\
\cline { 2 - 6 } & N & \% & N & \% \\
\hline Ischemic cases & 2 & 20 & 4 & 40 \\
\hline
\end{tabular}

\begin{tabular}{|l|c|c|c|c|}
\hline $\begin{array}{l}\text { Non-ischemic } \\
\text { cases }\end{array}$ & 1 & 10 & 6 & 60 \\
\hline $\begin{array}{l}\text { Undetermined } \\
\text { cases }\end{array}$ & 7 & 70 & 0 & 0 \\
\hline Total cases & 10 & 100 & 10 & 100 \\
\hline $\begin{array}{l}\text { Fisher's Exact } \\
\text { Test }\end{array}$ & \multicolumn{5}{|c|}{11.241} \\
\hline P. value & \multicolumn{4}{|c|}{$0.004^{*}$} \\
\hline
\end{tabular}

The macular ischemia was revealed in 2 cases by FA, but the significant macular ischemia was revealed in 6 cases in DCP by OCT-A which included the ischemic 2 cases detected by FA.

The relation between FA and OCT-A regarding DCP in detection of significant macular ischemia was highly statistically significant (table 5), this demonstrated that OCT-A is superior to FA especially when retina is obscured by extensive hemorrhage in cases of BRVO.

Table (5): The relation between FA and OCT-A regarding DCP in detection of significant macular ischemia after classification of cases according to ischemic condition.

\begin{tabular}{|l|c|c|c|c|}
\hline \multirow{2}{*}{} & \multicolumn{2}{|c|}{ FA } & \multicolumn{2}{c|}{$\begin{array}{c}\text { significant } \\
\text { macular ischemia } \\
\text { in DCP by OCT-A }\end{array}$} \\
\cline { 2 - 5 } & $\mathbf{N}$ & $\%$ & N & $\%$ \\
\hline Ischemic cases & 2 & 20 & 6 & 60 \\
\hline $\begin{array}{l}\text { Non-ischemic } \\
\text { cases }\end{array}$ & 1 & 10 & 4 & 40 \\
\hline $\begin{array}{l}\text { Undetermined } \\
\text { cases }\end{array}$ & 7 & 70 & 0 & 0 \\
\hline Total cases & 10 & 100 & 10 & 100 \\
\hline $\begin{array}{l}\text { Fisher's Exact } \\
\text { Test }\end{array}$ & \multicolumn{5}{|c|}{$0.005^{*}$} \\
\hline P. value & \multicolumn{5}{|c|}{} \\
\hline
\end{tabular}

A statistically significant difference was found between mean visual acuity in cases with macular ischemia detected by FA and mean visual acuity in cases in which FA didn't detect macular ischemia (Table 6),

A negative relation was found between mean visual acuity and macular ischemia detected by FA.

Table (6): Relation between visual acuity and macular ischemia detected by FA

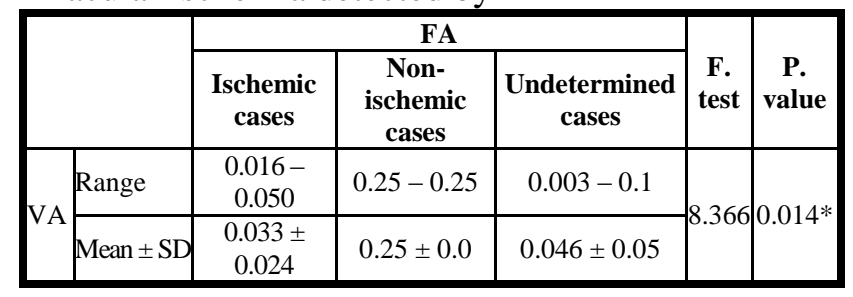


Although a negative relation was found between mean visual acuity and significant macular ischemia detected by OCT-A in the SCP (Table 7).

Table (7): Relation between significant macular ischemia in the SCP detected by OCT-A and VA.

\begin{tabular}{|l|l|c|c|c|c|}
\hline \multicolumn{2}{|c|}{} & \multicolumn{2}{|c|}{$\begin{array}{c}\text { Significant macular ischemia } \\
\text { in SCP by OCT-A }\end{array}$} & \multirow{2}{*}{ T. test } & \multirow{2}{*}{ P. value } \\
\cline { 3 - 5 } \multicolumn{2}{|c|}{} & $\begin{array}{c}\text { Ischemic } \\
\text { cases }\end{array}$ & $\begin{array}{c}\text { Non-ischemic } \\
\text { cases }\end{array}$ & & \\
\hline \multirow{2}{*}{ VA } & Range & $0.003-0.10$ & $0.008-0.250$ & \multirow{2}{*}{1.258} & 0.294 \\
\cline { 2 - 5 } & Mean \pm SD & $0.042 \pm 0.09$ & $0.096 \pm 0.087$ & & \\
\hline
\end{tabular}

A statistically significant difference was found between mean visual acuity in cases with significant macular ischemia detected in DCP by OCT-A and mean visual acuity in cases with nonsignificant macular ischemia (Table 8).

There is a negative relation between the mean visual acuity and the significant macular ischemia in the DCP detected by OCT-A (Table 8). Table (8): Relation between significant macular ischemia in the DCP detected by OCT-A and VA.

\begin{tabular}{|l|l|c|c|c|c|}
\hline \multirow{2}{*}{} & \multicolumn{2}{|c|}{$\begin{array}{c}\text { Significant macular ischemia } \\
\text { in DCP by OCT-A }\end{array}$} & \multirow{3}{*}{ T. test } & P. value \\
\cline { 3 - 5 } \multicolumn{2}{|c|}{} & $\begin{array}{c}\text { Ischemic } \\
\text { cases }\end{array}$ & $\begin{array}{c}\text { Non-ischemic } \\
\text { cases }\end{array}$ & & \\
\hline \multirow{2}{*}{ VA } & Range & $0.003-0.10$ & $0.1-0.250$ & 8.969 & $0.017^{*}$ \\
\cline { 2 - 5 } & Mean \pm SD & $0.032 \pm 0.037$ & $0.138 \pm 0.075$ & & \\
\hline
\end{tabular}

\section{DISCUSSION}

In our study the prevalence of hypertension was $50 \%$, this is consistent with Johnston et al (1985)6, who reported that the prevalence of hypertension in patients with BRVO is $37-79 \%$ in various series.

In our study, by OCT-A we found that most major BRVOs were ischemic. The same results were reported by Hayreh and Hayreh ${ }^{(7)}$, but by FA we found that non-ischemic BRVOs are more common, which is the same results as Liu and $\mathrm{Xu}{ }^{(8)}$. This accentuated the role of OCT-A in detection of macular ischemia in acute onset BRVO especially when the retina is obscured by retinal hemorrhage.

In our study we found that FA was not able to evaluate retinal ischemia due to hemorrhage in $70 \%$ of cases. Hayreh et al. ${ }^{(\mathbf{9})}$ found that in early RVOs, FA wasn't able to evaluate retinal ischemia in more than $1 / 3$ of the studied cases.

Although there was no difference in numbers of ischemic cases detected by OCT-A in SCP and DCP, the cases showed evident difference in size of the ischemic macular area and evident difference in VA, so we stated a standard of the significant macular ischemia by OCT-A. in our study we defined a standard of the significant macular ischemia by OCT-A as an area of macular ischemia extending from the FAZ equal to $3 \times 3 \mathrm{~mm} 2$ or a quadrant of $6 \times 6$ scan even there is macular edema within this area.

When we compared between SCP and DCP in detection of the significant macular ischemia by OCT-A according to our standard, OCT-A showed significant macular ischemia in DCP in 6 cases, but it showed significant macular ischemia in SCP in only 4 cases. This result is the same as the results of Coscas et al. ${ }^{(10)}$ who reported that OCT-A showed ischemia in deep plexus more than superficial plexus.

In our study, we observed that the OCT-A is superior to FA in evaluation of macular ischemia in both SCP and DCP, which were the same results reported by Suzuki et al. ${ }^{(11)}$ who reported that OCT-A is superior to FA in evaluation of macular ischemia in cases of macular hemorrhage.

In our study, macular ischemia detected by FA had a negative relation with VA. This was statistically significant. This result is consistent with that of Coscas et al. ${ }^{(\mathbf{1 0})}$ but they did not find the same relation by OCT-A.

Kang et al. ${ }^{(12)}$ and Wakabayashi et al. ${ }^{(13)}$ reported that ischemia in both SCP and DCP by OCT-A was negatively related with VA, and ischemia in the DCP having the stronger relation. Our study is consistent with their studies according to our standard of significant macular ischemia.

We found a negative relation between mean visual acuity and significant macular ischemia detected by OCT-A in the SCP, but without statistically significant difference.

This is explained by presence of another factor, which affected the VA which was the significant macular ischemia in DCP. This result confirms inability of SCP to evaluate macular ischemia alone and highlights the important role of DCP in detection of macular ischemia by OCT-A, especially when there is masking of retina by extensive hemorrhage in which FA was not able to evaluate it and described it as undetermined type.

In our study there was no difference between OCT-A and FA in detection of macular edema, both detected ME in all 10 cases (100\%)

We also observed that ME was present mainly in the DCP compared to SCP as reported by Spaide et al. ${ }^{(14)}$ who reported that sites of macular 
edema are mainly localized in the DCP in regions of reduced or absent flow.

\section{CONCLUSION}

Our study demonstrated that OCT-A was superior to FA in detection of macular ischemia as FA was not able to evaluate retina with extensive retinal hemorrhage and had intravenous dye injection side effects. Retinal ischemia in the DCP was more evident than that of SCP by OCT-A. Our study demonstrated that macular ischemia detected by both FFA and OCT-A related negatively with V.A. and OCT-A had stronger negative relation. In our study we stated a standard of significant macular ischemia detected by OCT-A. We demonstrated mathematically that $3 \times 3 \mathrm{~mm}$ OCT-A scan equal to 5 disc area by FA. We observed that all ischemic cases by FA respect this standard and shows significant macular ischemia by OCT-A. By this standard we explain the cause of decrease of VA in the cases that showed masking and could not be evaluate by FA. Description of retinal ischemia by this standard is more accurate. OCT-A has some side effects as its narrow field and the lack of dynamics present in FA such as leakage and AV transient time. We can say that OCT-A can replace FA in detection of retinal ischemia, in some cases, especially when macula is masked by intra retinal hemorrhage and FA cannot evaluate the retina.

\section{RECOMMENDATIONS}

Larger studies should be performed with long term follow up to determine the prognostic value of OCT-A. In cases of BRVO with significant retinal hemorrhage, OCT-A can be done instead of FA. OCTA can potentially replace FA when FA is contraindicated. Larger studies should be performed to evaluate the standard area of macular ischemia and classify significant ischemic versus non-ischemic BRVO, CRVO and other ischemic maculopathy.

\section{REFERENCES}

1. Klein BE, Klein R, Moss SE et al. (2000): The epidemiology of retinal vein occlusion. The Beaver Dam eye study. Trans Am Ophthalmol Soc.,98:133-143.

2. Beaumont PE, Kang HK (2002): Cup-to-disc ratio. intraocular pressure, and primary openangle glaucoma in retinal venous occlusion. Ophthalmology, 109.282-286.

3. Hayreh SS (1994): Retinal vein occlusion. Indian Ophthalmol, 42(3):109-132.
4. Balaratnasingam $C$, Mendis $K R, Y u P$ et al (2010): Correlation of histologic and clinical images to determine the diagnostic value of fluorescein angiography for studying retinal capillary detail. Invest Ophthalmol Vis Sci., 51:5864-5869.

5. Cooney MJ, Klancnik JM Jr, Spaide RF (2015): Retinal vascular layers imaged by fluorescein angiography and optical coherence tomography angiography. JAMA Ophthalmol., 133: 45-50.

6. Johnston R, Brucker AJ, Steinmann $W$ et al (1985): Risk factors of branch retinal vein occlusion. Arch Ophthalmol., 103:1831-1832.

7. Hayreh SS, Hayreh MS (1980): Hemi-central retinal vein occlusion. Pathogenesis, clinical features, and natural history. Arch Ophthalmol., 98:1600-1609.

8. Liu W, Xu L (2007): Vein occlusions in Chinese subjects. Ophthalmology, 114:1795-1796.

9. Hayreh SS, Klugman MR, Beri M et al. (1990): Differentiation of ischemic from nonischemic central retinal vein occlusion during the early acute phase. Graefes Arch Clin Exp Ophthalmol., 228(3):201-217.

10. Coscas F, Glacet-Bernard A, Miere A et al. (2016): Evaluation of superficial and deep capillary plexa. Optical coherence tomography angiography in retinal vein occlusion. Am J Ophthalmol.,161:160-171.

11. Suzuki N, Hirano Y, Yoshida M et al. (2016): Microvascular Abnormalities on Optical Coherence Tomography Angiography in Macular Edema Associated with Branch Retinal Vein Occlusion. Am J Ophthalmol.,161:126-132.

12. Kang JW, Yoo R, Jo YH, Kim HC (2016): Correlation of Microvascular Structures on Optical Coherence Tomography Angiography with Visual Acuity in Retinal Vein Occlusion. Retina.

13. Wakabayashi T, Sato T, Hara-Ueno $C$, Fukushima Y, Sayanagi K, Shiraki N et al. (2017): Retinal Microvasculature and Visual Acuity in Eyes with Branch Retinal Vein Occlusion. Imaging Analysis by Optical Coherence Tomography Angiography. Invest Ophthalmol Vis Sci., 58(4):2087-2094.

14. Spaide RF, Klancnik JM, Cooney MJ (2015): Retinal vascular layers imaged by fluorescein angiography and optical coherence tomography angiography. JAMA Ophthalmol., 133:45-50. 